\title{
Adesão às normas e condutas sobre biossegurança e controle de infecção no ensino da Odontologia: revisão de literatura
}

\author{
Adherence to standards and conducts about biosafety and infection \\ monitoring in dentistry teaching: literature review \\ Adherencia a las normas y conductas de bioseguridad y control de \\ infecciones en la enseñanza de la Odontología: revisión de literatura \\ Laura Moretto MOLINA ${ }^{1}$ \\ Luiz Fernando LOLLI $^{2}$ \\ Mitsue FUJIMAKI ${ }^{2}$ \\ Marcos Sérgio ENDO ${ }^{2}$ \\ Najara Barbosa da ROCHA ${ }^{2}$ \\ ${ }^{1}$ Graduanda, Departamento de Odontologia da Universidade Estadual de Maringá, UEM Maringá-PR, Brasil \\ ${ }^{2}$ Docente, Departamento de Odontologia da Universidade Estadual de Maringá, UEM Maringá-PR, Brasil
}

\begin{abstract}
Resumo
A Odontologia é uma das áreas de maior risco de ocorrência de acidentes ocupacionais, pois os profissionais estão em constante contato com o material biológico potencialmente contaminado oriundo dos atendimentos odontológicos. Por isso, o objetivo deste trabalho foi discutir a adesão às normas e condutas sobre biossegurança e controle de infecção, publicadas no Brasil, no ensino de Odontologia, por meio de uma revisão de literatura. Foi realizada uma revisão bibliográfica, por duas pesquisadoras independentes, na base de dados Biblioteca Virtual em Saúde em periódicos nacionais, com os seguintes descritores: biossegurança; odontologia; ensino. Após verificação dos critérios de inclusão e exclusão, foram selecionados para análise na íntegra 21 artigos, sendo excluídos 8 após a leitura, resultando em 13 artigos científicos. A partir desta revisão de literatura foi verificado que os estudantes das universidades de Odontologia, mesmo tendo o conhecimento sobre biossegurança, negligenciam de alguma forma as medidas de proteção, tornando-se mais expostos ao risco dos acidentes ocupacionais, principalmente com material perfurocortante. Os resultados mostraram que é de fundamental importância as instituições de ensino realizarem capacitação e educação permanente sobre o tema, a fim de atingir práticas adequadas para que se tornem hábitos na vida profissional destes graduandos.

Descritores: Exposição a Agentes Biológicos; Odontologia; Equipamentos de Proteção; Saúde do Trabalhador; Ensino; Revisão.
\end{abstract}

\begin{abstract}
Dentistry is one of the higher risks areas with occurrence of occupational accidents, because the professionals are in continuous contact with the biological material potentially infested coming from dental attendance. That's why the main of this paper was discuss adherence to the standards and conducts about biosafety and infection monitoring, published in Brazil, in dentistry teaching, by means of literature review. A bibliographical research was carried out, by two independent researchers, in data base of virtual library in health, in national periodicals, with the following descriptors: biosafety, dentistry, and teaching. After checking the criteria of inclusion and exclusion, 18 articles were selected for analysis in full, and 8 articles were excluded after reading, resulting in 10 scientific papers. From this literature review, it was checked that the students from dentistry universities, even getting the biosafety knowledge, neglect somehow the protection measures, becoming more exposed to occupational accidents, mainly with perforatingcutting material. The results showed that is fundamental important the education institutions perform training and constant education about the theme in order to reach correct practices and these measures become habits in these grader professional lives.

Descriptors: Exposure to Biological Agents; Dentistry; Protectives Devices; Occupational Health; Teaching; Review.

\section{Resumen}

La Odontología es una de las áreas de mayor risco de ocurrencia de accidentes ocupacionales, pues los profesional es están en constante contacto con el material biológico potencialmente contaminado oriundo de los atendimientos odontológicos. Por eso, el objetivo de este trabajo fue discutir a la adhesión las normas y conductas sobre bioseguridad y controle de infección, publicadas en Brasil, en la enseñanza de Odontología, por medio de revisión de literatura. Fue realizada una revisión bibliográfica, por dos investigadoras independientes, en la base de dados Biblioteca Virtual en Salud en periódicos nacionales, con los siguientes descriptores: bioseguridad; odontología; enseñanza. Después de la verificación de criterios de inclusión y exclusión, fueron seleccionados para análisis en la íntegra de 18 artículos, siendo excluidos 8 artículos tras la lectura, resultando en 10 artículos científicos. A partir de esta revisión de literatura fue verificado que los estudiantes de las universidades de Odontología, mismo tiendo lo conocimiento sobre bioseguridad, sin olvidar de algún modo las medidas de protección, tornando se más expuestos los riesgos de accidentes ocupacionales, principalmente con materiales corto-punzantes. Los resultados mostraran que es de fundamental importancia las instituciones de enseñanza realizar capacitación y educación permanente sobre el tema, a fin de atingir prácticas correctas y que estas medidas se tornen hábitos en la vida profesional de estos graduandos.

Descriptores: Exposición a Agentes Biológicos; Odontología; Equipo de Protección; Salud do Trabajador; Enseñanza; Revisión.
\end{abstract}

\section{INTRODUÇÃO}

Biossegurança é o conjunto de ações voltadas para a prevenção, minimização ou eliminação de riscos inerentes às atividades de pesquisa, produção, ensino, desenvolvimento tecnológico e prestação de serviços, que podem comprometer a saúde do homem, dos animais, do meio ambiente e até mesmo a qualidade dos trabalhos desenvolvidos ${ }^{1}$. É necessária principalmente para que os profissionais da saúde saibam se proteger de maneira correta de agentes infectantes em ambientes de risco. $\mathrm{Na}$ Odontologia, a biossegurança é uma área que deve ser estudada por todos os que exercem a profissão, de modo direto ou indireto, e ainda por aqueles que estão em constante contato com o material biológico potencialmente contaminado oriundo dos atendimentos odontológicos ${ }^{1}$. Isso deve-se ao fato do grande número de procedimentos em que o profissional está exposto quando atua na cavidade bucal, como saliva e sangue, além dos aerossóis, coloca esta profissão como uma das áreas de maior risco de ocorrência de acidentes ocupacionais ${ }^{2}$. Há um manejo frequente de instrumentos perfurocortantes, como bisturis e agulhas de 
anestesia, o uso da caneta de alta rotação para remoção de tecido dental ou materiais restauradores que produz uma grande quantidade de partículas em suspensão que estão em contato com o cirurgião dentista e o auxiliar ${ }^{3}$. Além disso, traz desafios não somente à equipe de saúde, mas também às empresas que investem em pesquisa ${ }^{4}$

O conhecimento a respeito do controle de infecções em Odontologia deve ser adequadamente ensinado e vivenciado pelos Cirurgiões-Dentistas (CD) durante o curso de graduação ${ }^{5}$. Dentre os estudantes da área da saúde, os graduandos em Odontologia são os mais acometidos por acidentes perfurocortantes ${ }^{1}$. Este risco é maior por estarem em processo de aprendizagem, podendo possuir pouca destreza e habilidade ao manusear os materiais ${ }^{2}$, possibilidade de utilização errônea de métodos de esterilização, falta de cuidados necessários, pois estão em fase de construção do conhecimento, além do aumento da resistência dos microrganismos, que colaboram para a elevação do número de casos de infeções ${ }^{6}$. Por isso os estudantes têm sido apontados como o grupo para o qual a educação em biossegurança e o controle de infecção cruzada são indispensáveis para correto treinamento e cumprimento dos protocolos rotineiramente ${ }^{7}$, sendo necessário que os currículos dos cursos da área da Saúde aumentem a importância das disciplinas de Biossegurança e Gerenciamento de Resíduos de Serviços de Saúde ${ }^{4}$.

Conhecer e estabelecer normas e condutas de biossegurança em instituições de ensino de Odontologia tem o intuito de subsidiar as equipes profissionais no repensar de sua prática na atenção à saúde bucal e apoiar as ações de vigilância. É importante padronizar condutas, orientar os docentes, discentes e funcionários das clínicas odontológicas sobre os cuidados necessários para desempenhar suas funções com segurança. Para o controle de infecção se tornar realmente efetivo, não é suficiente realizar procedimentos isolados. É necessário que todos sigam corretamente as condutas preventivas, pois qualquer comportamento inadequado pode causar uma contaminação ${ }^{4}$. Por isso, as instituições devem estabelecer normas para que cada pessoa tenha a responsabilidade e o dever de contribuir para que a qualidade dos trabalhos e que a segurança no ambiente seja alcançada, beneficiando a todos. Neste contexto, objetivou-se discutir a adesão às normas e condutas sobre biossegurança e controle de infecção publicadas no Brasil no ensino de Odontologia, por meio de revisão de literatura.

\section{MATERIAL E MÉTODO}

Foi realizada uma revisão bibliográfica, por meio do portal Biblioteca Virtual em Saúde (BVS; http://www.bireme.br/php/index.php), em periódicos nacionais, de modo a identificar as publicações sobre o tema biossegurança em Odontologia no contexto do ensino nacional. Justifica-se a escolha desta base por tratar-se de um banco de dados de referência brasileira para investigações na área da saúde. Foi realizada uma pesquisa na ferramenta de busca no próprio portal, na qual inserimos descritores como: exposição a agentes biológicos, Odontologia, equipamentos de proteção, saúde do trabalhador, ensino e revisão. Desta forma, buscou-se sistematizar e analisar os artigos de biossegurança relacionados com a temática educação, incluindo outros termos fundamentais como ensino, aprendizagem, capacitação/qualificação, formação, treinamento e práticas educacionais.
Os critérios de inclusão foram: estudos sobre normas e condutas sobre biossegurança e controle de infecção em odontologia; Publicações do período de 01 de janeiro de 2006 a 31 de março de 2017; trabalhos completos; idioma português, inglês ou espanhol; todos os tipos de estudos; estudos em cenários brasileiros. Os critérios de exclusão foram as publicações que não estavam referendadas como artigos científicos e manuais e também aquelas de caráter internacional. Foi escolhida a data a partir de 2006, pois há a publicação oficial do Ministério da Saúde ${ }^{3}$ sobre o assunto publicado nesta data que reúne os temas pertinentes a nossa pesquisa e os resultados da pesquisa foi comparada a este documento.

Os estudos foram levantados por duas pesquisadoras independentes em duas fases (NBR, LMM): 1) resumos e títulos foram selecionados e 2) os textos completos dos títulos selecionados foram obtidos e lidos para determinar o conjunto de amostra final $(n=15)$. As etapas foram realizadas de forma independentes e reunião de consenso entre os artigos foram realizadas entre as etapas e, em caso a discordância permanecida, esta foi sanada por um terceiro pesquisador.

A síntese dos dados foi realizada por cada pesquisador que preencheu um formulário padronizado no programa Microsoft Excel, com os seguintes dados do artigo: autores, ano de publicação, instituição brasileira de ensino, objetivos, resultados e conclusão.

\section{RESULTADOS}

A pesquisa com os descritores selecionados resultou em 125 artigos na base de dados Bireme. Após verificação dos critérios de inclusão e exclusão, foram selecionados para análise na íntegra 21 artigos, sendo excluídos 4 artigos (um que era internacional e três que não falavam especificamente de biossegurança), 3 estavam duplicados e 1 era livro. O resultado final da revisão foram 10 publicações, sendo todos classificados como artigos científicos (Tabela 1).

\section{DISCUSSÃO}

A biossegurança objetiva dotar os profissionais e as instituições das medidas e práticas que visem desenvolver as atividades com um grau de segurança adequado, reduzindo ou eliminando os riscos inerentes ao ambiente odontológico $^{8}$. É constante a preocupação em alertar o cirurgião dentista sobre a importância do cumprimento das normas universais de biossegurança nos consultórios odontológicos, como uso obrigatório de EPIs, monitoramento dos métodos de esterilização e imunização obrigatória na área de saúde e em instituições públicas e/ou privadas $^{6,9}$. Os docentes e discentes da Odontologia devem se manter bem informados porque frequentemente estão expostos a riscos biológicos e químicos que podem comprometer a saúde do homem, dos animais e do meio ambiente ${ }^{9}$.

Faz-se necessário a adoção de medidas de controle de infecção que tenham como principal objetivo conceber e implantar políticas e procedimentos que visem proteger o profissional e o paciente contra a transmissão de uma grande variedade de doenças infectocontagiosas. ${ }^{5}$. O presente estudo verificou que a maioria dos estudantes tinha conhecimento das normas $^{5,6,8,9}$. Outros estudos, porém, não relataram sobre este assunto ${ }^{10,12}$. As medidas de biossegurança devem ser adotadas na assistência odontológica de todos os pacientes. O estudo de Armond et 
al. ${ }^{1}$ relatou que $80,1 \%$ dos estudantes concordam com esta afirmação.

Tabela 1. Características dos artigos selecionados nesta revisão de literatura, após pesquisa na base de dados

\begin{tabular}{|c|c|c|c|c|}
\hline $\begin{array}{c}\begin{array}{c}\text { Autores } \\
\text { (ano) }\end{array} \\
\text { (anos }\end{array}$ & Local & Amostra & objetivo & Conclusão \\
\hline $\begin{array}{l}\text { Armond } \\
\text { et al. } \\
(2016)^{1}\end{array}$ & $\begin{array}{l}\text { Universidade } \\
\text { Federal dos } \\
\text { Vales do } \\
\text { Jequitinhonha e } \\
\text { Mucuri }\end{array}$ & $\begin{array}{c}156 \\
\text { alunos } \\
17 \\
\text { técnicos } \\
19 \\
\text { docentes } \\
7 \text { setor } \\
\text { limpeza } \\
\end{array}$ & 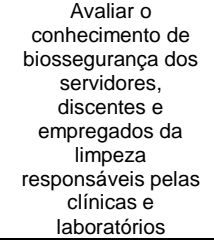 & 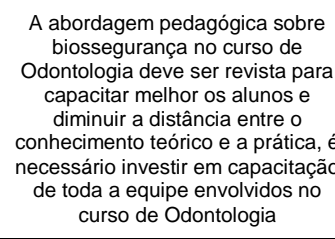 \\
\hline $\begin{array}{l}\text { Lages } \\
\text { et al. } \\
(2015)^{4}\end{array}$ & $\begin{array}{l}\text { Centro } \\
\text { Universitário } \\
\text { CESMACa } \\
\text { Univeridadade } \\
\text { Federal de } \\
\text { Alagoas }\end{array}$ & $\begin{array}{l}224 \\
\text { alunos }\end{array}$ & 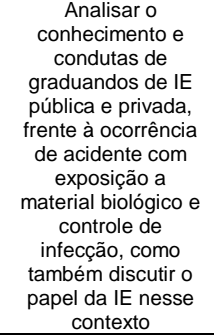 & 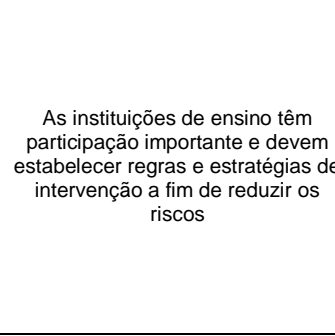 \\
\hline $\begin{array}{l}\text { Tomo } \\
\text { et al. } \\
(2014)^{5}\end{array}$ & $\begin{array}{l}\text { Universidade } \\
\text { Camilo Castelo } \\
\text { Branco- } \\
\text { Campus } \\
\text { Fernandópolis }\end{array}$ & $\begin{array}{l}374 \\
\text { alunos }\end{array}$ & 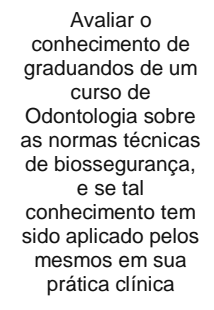 & 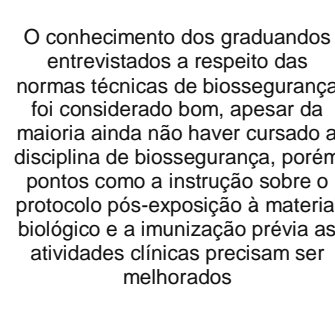 \\
\hline $\begin{array}{l}\text { Silva } \\
\text { et al. } \\
(2007)^{7}\end{array}$ & $\begin{array}{l}\text { Faculdade de } \\
\text { Odontologia de } \\
\text { Araraquara } \\
\text { (Unesp) e } \\
\text { municipio de } \\
\text { Araraquara }\end{array}$ & $\begin{array}{c}112 \\
\text { alunos } \\
38 \text { CDs } \\
22 \\
\text { auxiliares }\end{array}$ & 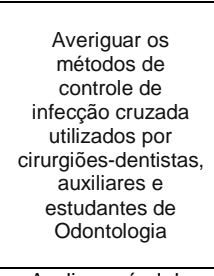 & 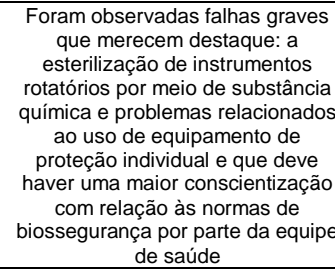 \\
\hline $\begin{array}{l}\text { Xerez } \\
\text { et al. } \\
(2012)^{8}\end{array}$ & $\begin{array}{l}\text { Universidade } \\
\text { Federal do Rio } \\
\text { Grande do Norte }\end{array}$ & $\begin{array}{l}358 \\
\text { alunos }\end{array}$ & 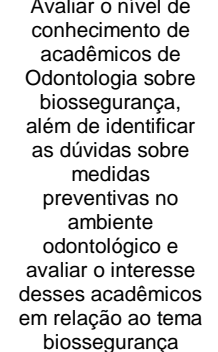 & 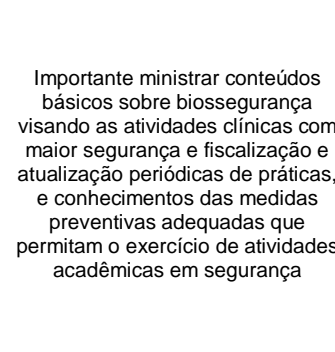 \\
\hline $\begin{array}{l}\text { Schroeder } \\
\text { et al. } \\
(2010)^{9}\end{array}$ & $\begin{array}{l}\text { Universidade da } \\
\text { Região de } \\
\text { Joinville } \\
\text { (Univille) } \\
\end{array}$ & $\begin{array}{l}142 \\
\text { alunos }\end{array}$ & $\begin{array}{l}\text { Avaliar o grau de } \\
\text { importância da } \\
\text { biosseguranga na } \\
\text { visãoo dos alunos } \\
\end{array}$ & 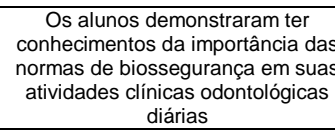 \\
\hline $\begin{array}{l}\text { Lima } \\
\text { et al al } \\
(2008)^{10}\end{array}$ & $\begin{array}{l}\text { Universidade } \\
\text { Federal da } \\
\text { Paraiba }\end{array}$ & $\begin{array}{l}168 \\
\text { alunos }\end{array}$ & 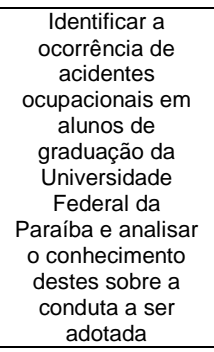 & 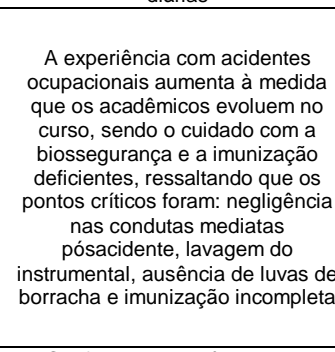 \\
\hline $\begin{array}{l}\text { Oliveira } \\
\text { et al } \\
(2010)^{11}\end{array}$ & $\begin{array}{l}\text { Faculdaded de } \\
\text { Odontlogiag de } \\
\text { Pernambuco }\end{array}$ & 87 alunos & 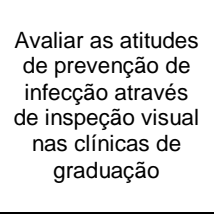 & 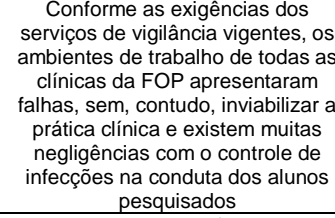 \\
\hline $\begin{array}{l}\text { Pimentel } \\
\text { et at } \\
(2012)^{12}\end{array}$ & 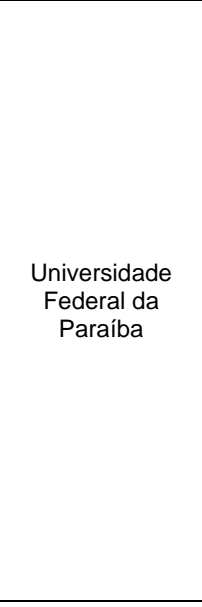 & $\begin{array}{l}117 \\
\text { alunos }\end{array}$ & 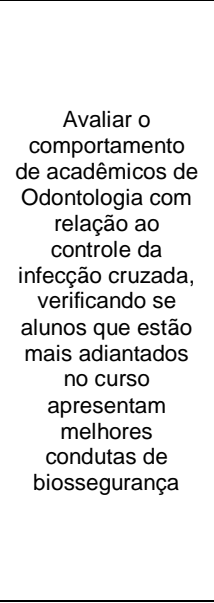 & 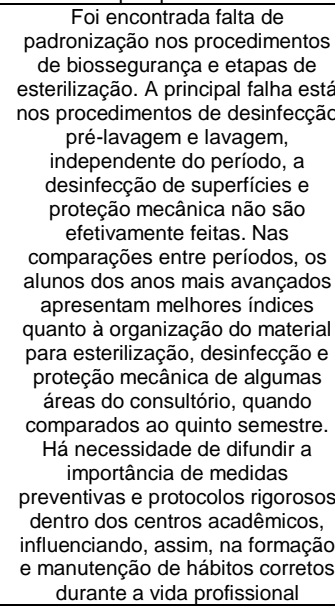 \\
\hline $\begin{array}{l}\text { Letieri } \\
\text { et al } \\
(2011)^{13}\end{array}$ & $\begin{array}{l}\text { Universidade } \\
\text { Federal do Rio } \\
\text { de Janeiro }\end{array}$ & $\begin{array}{l}169 \\
\text { alunos }\end{array}$ & $\begin{array}{l}\text { Verificar a } \\
\text { aderencia às } \\
\text { normas de } \\
\text { controle de } \\
\text { infeccalo pelo } \\
\text { corpo discente }\end{array}$ & $\begin{array}{l}\text { A maioria dos procedimentos em } \\
\text { controle de infeçōes foi adotada a } \\
\text { por grande parte dos alunos, sem } \\
\text { distinçao de periodol letivo, mas } \\
\text { ainda existem várias atitudes que } \\
\text { necessitam ser aprimoradas } \\
\end{array}$ \\
\hline
\end{tabular}

De acordo com o manual da ANVISA ${ }^{3}$, precauçõespadrão são medidas de prevenção que devem ser utilizadas independentes de diagnóstico confirmado ou presumido de doença infecciosa transmissível no indivíduo-fonte. As seguintes medidas devem ser adotadas na assistência a todos os pacientes: utilizar equipamentos de proteção individual (EPI); lavar as mãos antes e após o contato com o paciente e entre dois procedimentos realizados no mesmo paciente; manipular cuidadosamente o material perfurocortante; não reencapar, entortar, quebrar ou retirar as agulhas das seringas; transferir os materiais e artigos, durante o trabalho a quatro mãos, com toda a atenção e, sempre que possível, utilizando-se uma bandeja; manter as caixas de descarte dispostas em locais visíveis e de fácil acesso e não preenchê-las acima do limite de $2 / 3$ de sua capacidade total; efetuar o transporte dos resíduos com cautela para evitar acidentes; não afixar papéis em murais utilizando agulhas; descontaminar as superfícies com desinfetantes preconizados pelo controle de infecção, caso haja presença de sangue ou secreções potencialmente infectantes; submeter os artigos utilizados à limpeza, desinfecção e/ou esterilização, antes de serem utilizados em outro paciente; não tocar os olhos, nariz, boca, máscara ou cabelo durante a realização dos procedimentos ou manipulação de materiais orgânicos, assim como não se alimentar, beber ou fumar no consultório; manter os cuidados específicos na coleta e manipulação das amostras de sangue; durante os procedimentos (com luvas), não atender telefones, abrir portas usando a maçaneta nem tocar com as mãos em locais passíveis de contaminação. Porém alguns profissionais não seguem estas medidas de biossegurança, citando como principais razões a falta de tempo, a falta de conhecimento sobre determinados assuntos e por não acharem o procedimento necessário ${ }^{13}$.

$\mathrm{O}$ estudo de Xerez et al. ${ }^{8}$ mostrou que as dúvidas sobre a biossegurança em ambiente odontológico foram em relação aos procedimentos de esterilização e aos procedimentos pós-exposição aos acidentes. É importante ressaltar que todas as etapas das normas de controle da infecção são importantes e precisam ser utilizadas concomitantemente, não sendo dispensada nenhuma etapa anterior ou seguinte ${ }^{12}$.

O EPI é todo dispositivo ou produto de uso individual utilizado pelo trabalhador, destinado à proteção de riscos suscetíveis de ameaçar a segurança e a saúde no trabalho, com seu uso indicado durante o atendimento ao paciente, nos procedimentos de limpeza do ambiente e no reprocessamento dos $\operatorname{artigos}^{4}$. Em relação ao EPI, quase todos os trabalhos citaram sobre este assunto 1,4-6,10,11,13. Oliveira et al. ${ }^{11}$ citaram que para o atendimento clínico devem ser observados cuidados, como: lavagem das mãos com sabonete líquido de característica antisséptica, antes e após qualquer procedimento; secagem das mãos com papel toalha; uso adequado de EPI e de luvas descartáveis. As luvas devem ser usadas em todos os procedimentos, com todos os pacientes, para contato com materiais, instrumentos e equipamentos contaminados e durante o processo de limpeza desses materiais e do ambiente. As máscaras devem ser com filtro duplo, descartáveis e de tamanho suficiente para cobrir completamente a boca e o nariz. Os óculos com proteções laterais devem ser utilizados por todos os membros da equipe odontológica e pelo paciente. Eles verificaram que em relação à proteção do operador antes do atendimento, a maioria utilizava protetor ocular com vedação lateral $(78,2 \%)$; jaleco, gorro, máscara e luvas (100\%); utilizava babador $(57,3 \%)$; retirava joias/relógio antes do atendimento $(51,7 \%)$; lavava as mãos antes do atendimento $(58,6 \%)$; colocava saco de lixo no porta- 
detritos $(63,2 \%)$. No estudo de Tomo et al. ${ }^{5}$ os autores observaram que a maioria dos alunos afirmou também utilizar os EPIs no ambiente clínico por considerarem importante a prevenção de acidentes. No estudo de Letieri et al. ${ }^{13}$ em relação aos EPIs, quase todos os entrevistados utilizavam os materiais sugeridos. No estudo de Silva et al. ${ }^{7}$ foi verificado que $83 \%$ dos estudantes responderam que usavam a paramentação, além de desinfecção, esterilização e proteção do campo para evitar a contaminação cruzada, porém nenhum dentista mencionou a utilização de óculos de proteção, o que é uma falha no protocolo de proteção à contaminação do próprio profissional. No estudo de Armond et al. ${ }^{1}$, 10,9\% não faziam uso completo de EPI. Lages et al. ${ }^{4}$ mencionaram que a maioria dos alunos das instituições de ensino particular e pública utilizavam jaleco, luvas, máscara e gorro, entretanto, quanto à utilização de óculos de proteção, isso não acontece. Lima et al.10 citam que os estudantes dizem que o embaçamento dos óculos de proteção atrapalha.

A lavagem das mãos é o procedimento mais importante para prevenir e controlar infecções no serviço de saúde. A higienização das mãos com água e sabão deve ser escolhida sempre que houver umidade ou sujidade visível nas mãos. O álcool só deve ser aplicado quando as mãos estiverem livres de sujidade ou umidade visível ${ }^{4}$. No estudo na $\mathrm{FO} / \mathrm{UFRJ}^{13}$, quase a totalidade dos alunos usam sabão líquido e papel-toalha, para lavar e secar as mãos, respectivamente, e esses itens estão sempre à disposição nos boxes de atendimento. A lavagem das mãos continua sendo indicada ao iniciar e terminar as atividades clínicas, após usar o sanitário e sempre que as mãos estiverem sujas. Para as situações entre pacientes, a higienização das mãos com antissépticos alcoólicos nas mãos secas seria considerada como primeira opção para a redução da carga bacteriana das mãos dos profissionais de saúde ${ }^{13^{3}}$.

Os profissionais de saúde por estarem mais expostos possuem um risco maior de contrair doenças contagiosas, por isso o uso de vacinas para imunização, é uma barreira indispensável. No estudos de Armond et al. ${ }^{1}$, Schroeder et al. ${ }^{9}$, Tomo et al. ${ }^{5}$, Letieri et al. ${ }^{13}$ e Lages et al. ${ }^{4}$ mostraram que a maioria dos estudantes de Odontologia haviam sido vacinados contra a hepatite, sendo que no estudo de Schroeder et al. $(2010)^{9}$ mostraram que grande parte $(83,8 \%)$ dos graduandos têm conhecimento sobre a importância da imunização para a prevenção de sua saúde. Somente no estudo de Lima et al. ${ }^{10}$ a imunização completa para a hepatite B e tétano não foi realizada por grande parte dos estudantes. Além da vacinação, é muito importante a realização do teste anti-HBs para comprovar a resposta vacinal, principalmente pelos indivíduos envolvidos na área da saúde . Em alguns estudos $^{1,4,13}$ demonstraram que a sorologia pós-vacina para verificar a soroconversão não foram realizadas pela quase totalidade dos alunos. Em particularidade no estudo de Lages et al. ${ }^{4}$, que pesquisou alunos das duas instituições de ensino (particular e pública), foi verificado que em ambas as instituições a maioria dos alunos relatou ter recebido o esquema completo de três doses, sendo que na faculdade particular quase todos fizeram a sorologia após a vacina e uma minoria da faculdade pública. A confirmação da imunidade tem relação direta com a segurança em um possível acidente, uma vez que o acidentado pode não apresentar títulos protetores de anticorpos.

Muita atenção deve ser dada ao processo de limpeza e esterilização dos instrumentos ${ }^{6}$. A desinfecção é um procedimento físico ou químico que visa a eliminação da maioria dos micro-organismos patogênicos de superfícies e objetos $^{3}$. O protocolo de desinfecção a ser seguido após o atendimento odontológico começa com a eliminação de todo material descartável, devendo todos os materiais perfurocortantes serem dispensados em recipientes apropriados (tipo Descarpack). Seguidamente deve-se colocar o instrumental contaminado em recipientes contendo uma solução de detergente enzimático, por um mínimo de 10 minutos, devendo ser lavados (utilizando-se luvas grossas e paramentação), secos e acondicionados em caixas metálicas perfuradas e enviados para esterilização em autoclave $^{8}$. A desinfecção do instrumental precisa ser realizada antes do processo de lavagem, com o intuito de diminuir o risco de infecção por parte daquele que fará a limpeza, é importante no intuito de diminuir a virulência dos micro-organismos contidos nos instrumentais, proporcionando uma lavagem com menor risco de contaminação ${ }^{12}$.

De acordo com o manual proposto pela Anvisa ${ }^{3}$, em relação à limpeza de artigos, há duas maneiras a ser realizadas: limpeza manual que consiste em limpar manualmente a sujeira, por meio de uma aplicação de ação física, com a ajuda de detergentes e escovas e limpeza mecânica baseia-se em um procedimento automatizado para remover a sujeira com o auxílio de lavadoras com jato de água ou também lavadoras de ultrassom de baixa frequência, variando a temperatura e o tempo. No estudo de Pimentel et al. ${ }^{12}$ apontaram que a etapa de desinfecção prélavagem foi bastante negligenciada e $94 \%$ dos estudantes não a realizam. Quanto à lavagem prévia à esterilização, a maior parte $(86,2 \%)$ fazia com frequência e $10,3 \%$ fazem quando o material está visivelmente sujo. A utilização de luvas emborrachadas para este fim era rotina de apenas uma minoria de estudantes $(2,5 \%)$, enquanto $91,2 \%$ realizam a lavagem com luvas de procedimento e $6,2 \%$ não usam nenhuma proteção. A utilização de luvas emborrachadas de espessura grossa, para realização da lavagem dos instrumentais, é de suma importância e assegura maior proteção contra perfuração ou corte $e^{4,12}$. Durante a limpeza é necessária a completa paramentação do profissional para não ter o risco de acidentes com materiais biológicos, porém isso não é uma realidade em alguns estudos ${ }^{4,12,13}$. No estudo de Letieri et al. ${ }^{13}$ muitos estudantes entrevistados não usam as proteções durante a limpeza do instrumental contaminado. Na pesquisa de Oliveira et al. ${ }^{11}$ verificaram que a maioria dos estudantes lavava os instrumentais com detergente/sabão da clínica $(83,9 \%)$ e com luva de procedimento $(51,7 \%)$. No estudo de Lages et al. ${ }^{4}$ a utilização de luvas emborrachadas de espessura grossa, apropriadas para realização da limpeza dos instrumentais, foi referida pela maioria dos alunos da faculdade particular (97\%), enquanto que na faculdade estadual apenas 50\% dos alunos relataram fazer uso das luvas apropriadas.

A esterilização é o processo que tem por finalidade eliminar todo e qualquer micro-organismo existente, por meio de processos físicos ou químicos ${ }^{3}$. Existem dois tipos de esterilização dos instrumentais pelo calor úmido (autoclave) e o calor seco (estufa). Estudo de Silva et al. ${ }^{7}$ indicou que os estudantes utilizavam mais estufas para a esterilizar devido sua disponibilidade. Tomo et al. ${ }^{5}$ (2014) mostraram que grande parte $(54,27 \%)$ dos estudantes afirmou conhecer a estufa como um meio de esterilização em Odontologia. A esterilização em autoclave seria o método comercialmente mais indicado para o consultório odontológico $^{13}$ e para seu uso, os profissionais devem sempre utilizar luvas, jalecos, óculos e máscaras para evitar 
qualquer tipo de contaminação biológica no manuseio do material. Pimentel et al. ${ }^{12}$ observaram que os alunos não têm o hábito de separar seus instrumentais por procedimentos ou por número de pacientes previamente programados, pois $31,6 \%$ esterilizam todo o material. Deve-se ter conhecimento que mesmo materiais não utilizados no paciente são considerados contaminados pela deposição de aerossóis oriundos de procedimentos clínicos. Atualmente não se recomenda utilizar meios químicos para a esterilização de materiais odontológicos e todos devem ser submetidos à esterilização, porém um estudo apontou a utilização ainda destes produtos químicos ${ }^{6}$. Isso se deve porque estes meios químicos causam problemas ocupacionais para os profissionais com seu uso contínuo, além de promover alterações morfológicas nas fresas, como oxidação e corrosão. Considerando que os demais métodos, além de serem comprovadamente eficientes, requerem menor tempo para a esterilização e não promovem modificações na maioria dos instrumentos, não haveria motivos para a imersão em substâncias desinfetantes ${ }^{6}$.

Devemos dar atenção também a limpeza de superfícies para o controle de infecção e deve ser realizada com água e sabão neutro e a desinfecção com álcool a $70 \%$. Para minimizar a contaminação nas superfícies e em áreas vulneráveis, como os botões de acionamento dos diferentes equipamentos, sujeitos a danos elétricos, as recomendações revisadas do Central Diseases Control (CDC) sugerem o recobrimento destas superfícies com campos de algodão esterilizados para procedimentos cirúrgicos e a aplicação de barreiras impermeáveis durante a realização de procedimentos clínicos ${ }^{3}$. A desinfecção de superfícies precisa ser aplicada em pontos nos quais haja contato direto ou mesmo indireto, por ação de aerossóis com o cirurgião durante o atendimento ${ }^{12}$. No estudo de Pimentel et al. ${ }^{12}$ os resultados obtidos mostraram que a desinfecção de superfícies dentro do consultório é feita rotineiramente por $52,1 \%$ dos alunos, $41,0 \%$ realizam às vezes e $6,8 \%$ nunca realizam esse procedimento. $\mathrm{O}$ descuido com a limpeza de certas partes do consultório torna essas regiões potenciais focos de disseminação e contaminação. Normalmente a não utilização da barreira mecânica é relatada como decorrente de redução de custos e falta de hábito ${ }^{12}$. A desinfecção química da cadeira odontológica e das superfícies do ambiente deve ser feita entre cada consulta, pois reduz o risco de contaminação cruzada no ambiente ${ }^{13}$. Na UFRJ, um pouco mais da metade dos alunos entrevistados não realizavam o procedimento, sendo considerado não satisfatório para a biossegurança. A troca dessa proteção deve ser feita a cada paciente, neste estudo $49,6 \%$ dos alunos a realiza, enquanto $50 \%$ utilizam a mesma barreira em um turno completo de atendimento. A remoção desta barreira ao final do atendimento é um hábito que deve ser reforçado e infelizmente só foi feita por uma quantidade pequena de alunos ${ }^{13}$. Oliveira et al. ${ }^{11}$ também mostraram que a maioria dos alunos não desinfetava os objetos que ficavam sobre o equipo.

As barreiras físicas de tecido ou as plásticas impermeáveis devem ser trocadas a cada paciente. Sobre recobrimento de superfícies, Oliveira et al. ${ }^{11}$ verificaram que a maioria dos estudantes fez: recobrimento dos braços $(87,4 \%)$; recobrimento das alças do refletor $(94,3 \%)$; recobrimento das peças de mão: tríplice $(75,9 \%)$; recobrimento da bandeja auxiliar $(97,7 \%)$ e mesa auxiliar (70,1\%); usou ponta do sugador descartável $(97,7 \%)$. Menos da metade dos alunos fez: recobrimento das peças de mão: alta rotação $(40,2 \%)$ e micromotor $(39,1 \%)$; recobrimento da mangueira do sugador $(43,7 \%)$.

Os acidentes perfurocortantes com contaminação com material biológico são frequentes na prática clínica odontológica, por muitas vezes sendo negligência dos profissionais em relação aos métodos preventivos ${ }^{5}$. A não adesão das medidas preventivas é um dos agravantes que contribuem para a ocorrência de acidentes ${ }^{1}$. O grande número de acidentes ocupacionais está diretamente relacionado ao uso incompleto do $\mathrm{EPI}^{10}$. No estudo de Armond et al. ${ }^{1}, 25,6 \%$ dos discentes já sofreram acidente com perfurocortantes, $55,8 \%$ relatam que não saberiam se portar diante um acidente durante o atendimento e $83,3 \%$ interromperiam o atendimento diante de um acidente com material perfurocortante potencialmente infectado. A conduta a ser realizada diante aos acidentes com material biológico deve iniciar pela lavagem exaustiva com água e sabão o ferimento ou a pele exposta ao sangue ou fluído orgânico. As mucosas devem ser lavadas com soro fisiológico ou água em abundância; não deve ser provocado maior sangramento do local ferido e não se deve aumentar a área lesada, a fim de minimizar a exposição ao material infectante. O uso de antissépticos tópicos do tipo PVPI ou álcool $70 \%$ pode ser adotado. Não é recomendada a utilização de agentes cáusticos ou injeção de antissépticos. Deve-se procurar imediatamente o Centro de Referência no atendimento de acidentes ocupacionais com material biológico mais próximo para a realização do teste rápido no paciente fonte ${ }^{3,5}$. No estudo de Lima et al. ${ }^{10}$ verificou-se que a atitude dos cirurgiões-dentistas e auxiliares foi deficiente, uma vez que a conduta mais realizada foi a lavagem do local $(98,0 \%)$ e os cuidados mediatos foram negligenciados, pois apenas $10,8 \%$ procuraram tratamento, 20,0\% realizaram os exames sorológicos e apenas $1,5 \%$ realizou a quimioprofilaxia. Também foi observado que a experiência com acidentes ocupacionais aumentou com o evoluir dos períodos letivos de $78,2 \%$ no $3^{\circ}$ ano para $91,2 \%$ no $5^{\circ}$ ano. $\mathrm{O}$ aumento com relação aos períodos pode estar relacionado à passagem por um número maior de clínicas e carga horária cumulativa de atividades práticas. Na pesquisa de Tomo et al. ${ }^{5}$ um número considerável de alunos afirmou não saber exatamente como evitar um acidente na prática clínica (42,3\%), a maioria das dúvidas dos estudantes $(27,27 \%)$ foi sobre como agir caso algum acidente ocorrer e um número considerável de alunos $(42,06 \%)$ afirmou não saber como proceder caso sofra algum acidente. Lages et al. ${ }^{4}$ relataram que os alunos da universidade privada sofrem menos acidentes $(7,5 \%)$ que os alunos da universidade pública (20\%), com diferença significante entre eles $(p=0,0087)$. A maioria dos estudantes das duas instituições informou ter recebido orientações, mas quanto ao conhecimento da existência de um protocolo a ser seguido, em caso de acidentes na instituição, observa-se que $96,27 \%$ dos alunos da universidade privada e $60 \%$ da universidade pública responderam $\operatorname{sim}(\mathrm{p}<0,05)$. A notificação do acidente não ocorreu em $30 \%$ dos alunos da universidade privada e em $60,71 \%$ da pública. A subnotificação é uma realidade nos casos de acidentes com material biológico, no qual muitos casos não são notificados e encaminhados corretamente.

Apenas um estudo investigou sobre o descarte de resíduos $^{13}$. Os resíduos gerados nos serviços odontológicos causam risco à saúde pública e ao ambiente. Podem ser classificados em biológicos, químicos, perfurocortantes ou escarificantes e comuns ${ }^{4}$. Resíduos biológicos são aqueles com possíveis presenças de agentes biológicos, que por suas características podem apresentar risco de infecção, por isso devem ser acondicionados em sacos brancos com 
identificação, que devem ser substituídos quando atingirem $2 / 3$ de sua capacidade e serem submetidos a processos físicos para reduzir ou eliminar a carga microbiana ${ }^{3}$. Resíduos químicos contêm substâncias químicas que podem apresentar risco à saúde pública ou ao meio ambiente, dependendo de suas características de inflamabilidade, corrosividade, reatividade e toxicidade. Quando não forem submetidos a processo de reutilização, recuperação ou reciclagem devem ser submetidos a tratamento e disposição final específicos ${ }^{3}$. Resíduos perfurocortantes ou escarificantes são todos os objetos e instrumentos contendo cantos, bordas, pontos ou protuberâncias rígidas e agudas capazes de cortar ou perfurar (bisturis, agulhas, ampolas de vidro, brocas, limas endodônticas, pontas diamantadas e outros). Devem ser acondicionados em recipientes rígidos, com tampa vedante, estanques, resistentes à ruptura e à punctura $^{3}$. No estudo de Letieri et al. ${ }^{13}$ os resultados mostraram que todos os alunos realizam o descarte desta forma. Resíduos comuns são aqueles resíduos que não apresentam risco biológico, químico ou radiológico à saúde ou ao meio ambiente, podendo ser equiparados aos resíduos domiciliares e em sacos de lixo comum ${ }^{4}$.

Mesmo diante da resistência natural aos procedimentos de biossegurança, é preciso que os profissionais acreditem e invistam na aplicação de medidas de prevenção. A busca da qualidade clínica, com a consequente capacitação, coloca o profissional em posição diferenciada, atento às exigências terapêuticas e de biossegurança atuais ${ }^{6}$. No estudo de Silva et al. ${ }^{7}$ a maioria dos estudantes considera importante uma maior divulgação sobre os métodos para o controle de infecção. Quase metade dos alunos do estudo de Armond et al. ${ }^{1}$ julgam que a as informações que recebem sobre biossegurança não são suficientes para uma prática clínica segura. Schroeder et al. ${ }^{9}$ verificaram que os acadêmicos participantes deste estudo demonstraram, com suas respostas, a necessidade de cursos e/ou palestras sobre biossegurança para se sentirem atualizados e prevenidos para trabalhar no dia-a-dia de seus consultórios com segurança. Silva et al. ${ }^{7}$, Letieri et al. ${ }^{13}$, Tomo et al. ${ }^{5}$ e Xerez et al. ${ }^{8}$ ressaltaram que os acadêmicos precisam ser instruídos em relação às normas de biossegurança. Lages et al. ${ }^{4}$ alertam sobre a necessidade de reavaliar currículos, para que o conhecimento relacionado à saúde ocupacional esteja presente em todo o decorrer do curso. Armond et al. ${ }^{1}$ apontam que há a necessidade também de capacitar o corpo docente para transmitir o conhecimento de biossegurança de forma correta e praticálo a fim de reduzir o espaço entre o conhecimento teórico e prático, dando exemplo para os estudantes. Conhecer e compreender os processos de ensino da biossegurança é um importante instrumento estratégico pedagógico, visto a defasagem atual entre o mundo da escola e o do trabalho, no que se refere à biossegurança. Este fato influencia, sobremaneira, a formação profissional nessa área e com impactos significativos no mercado de trabalho ${ }^{1}$.

Um fato que potencializa a adesão do estudante às normas do controle de infecção é a obrigatoriedade e a fiscalização, as quais não devem ser negligenciadas, uma vez que os hábitos e atitudes adquiridos no curso irão nortear a sua futura conduta profissional ${ }^{5,8,12,13}$. Letieri et al. ${ }^{13}$ e Armond et al. ${ }^{1}$ mostraram que não houve diferença significativa em relação às condutas investigadas entre os alunos de diferentes períodos acadêmicos. Isto sugere que a aderência as normas de controle de infecção não estão associadas apenas aos conhecimentos, que deveriam ser melhores nos últimos períodos do curso.
Apesar das limitações do estudo, por ser uma revisão de literatura, os dados apresentados abrem novos questionamentos e direcionam para outros estudos em relação ao assunto abordado. Espera-se que este estudo proporcione subsídios para o planejamento e revisão de condutas e protocolos relativos à biossegurança e controle de infecção cruzada e ajude nas orientações sobre o tema no ensino de odontologia brasileiro.

\section{CONCLUSÃO}

Conclui-se que é de fundamental importância o conhecimento, a prevenção e prática sobre a biossegurança, visto que é um meio que divide a saúde da doença, da contaminação, da infecção, e ainda hoje há muitas práticas que são negligenciadas pelos profissionais. A partir desta revisão de literatura foi verificado que os estudantes das universidades de Odontologia, mesmo tendo o conhecimento sobre biossegurança, tem negligenciado de alguma forma as medidas de proteção, com isso estão mais expostos ao risco de acidentes com material perfurocortante. É importante que as instituições de ensino realizem educação permanente sobre o tema e modifiquem seus currículos para um ensino mais completo sobre biossegurança odontológica, a fim de atingir práticas adequadas sobre o tema e, consequentemente, ter um efetivo controle de infecção cruzada, para que estas medidas se tornem hábitos na vida profissional destes graduandos.

\section{REFERÊNCIAS}

1. Armond ACV, Gonçalves PF, Flecha OD, Oliveira DWD de, Sampaio FC, Falci SGM. Conhecimentos de biossegurança para as principais atividades de risco envolvendo servidores públicos, discentes e empregados da limpeza do curso de odontologia da UFVJM/Diamantina. RBOL. 2016; 3(2):32-52.

2. Silva JA, Paula VS, Almeida AJ, Villar LM. Investigação de acidentes biológicos entre profissionais de saúde. Esc Anna Nery Rev Enferm. 2009; 13(3):50816.

3. Brasil. Ministério da Saúde. Agência Nacional de Vigilância Sanitária. Serviços Odontológicos: Prevenção e Controle de Riscos / Ministério da Saúde, Agência Nacional de Vigilância Sanitária. - Brasília: Ministério da Saúde, 2006.

4. Ramos Lages SM, Santos AF, Silva Junior FF, Costa JG. Formação em odontologia: O papel das instituições de ensino na prevenção do acidente com exposição a material biológico. Cienc Trab. 2015; 17(54):182-7.

5. Tomo S, Boer NP, Correia TM, Silva WR, Lima DP, Cunha-Correia AS. Conhecimento de graduandos em Odontologia a respeito das normas de biossegurança. Arch Health Invest. 2014; 3(4):9-17.

6. Clementino FS, Gomes LB, Vianna RPT, Marcolino EC, Araújo JP, Chaves TV. Acolhimento na Atenção Básica: Análise a partir da avaliação externa do programa de melhoria do acesso e da qualidade da Atenção Básica (Pmaq-Ab). Rev Saúde e Ciência Online. 2015;4(1):62-80.

7. Silva RHBT, Santi MR, Pinelli LAP, Pita APG, Fais LMG. Levantamento dos métodos de controle de infecção cruzada utilizados pelos cirurgiões-dentistas, auxiliares estudantes de odontologia do município de Araraquara-SP. RFO Passo Fundo. 2007; 12(2):7-12.

8. Xerez JE, Galvão HC, Maia CADM, Gordón-Núñez MA, Silva Júnior FL da, Costa Neto H. Perfil de acadêmicos de odontologia sobre biossegurança. Rev 
Fac Odontol Porto Alegre. 2012; 53(1):11-5.

9. Schroeder MDS, Marin C, Miri F. Biossegurança: grau de importância na visão dos alunos do curso de graduação de Odontologia da Univille. Rev Sul-Bras Odontol. 2010. 7(1):20-6.

10. Lima AA, Azevedo AC, Fonseca AGL, Silva JLM, Padilha WWN. Acidentes ocupacionais: conhecimento, atitudes e experiências de estudantes de Odontologia da Universidade federal da Paraíba. Pesq Bras Odontoped Clin Integr. 2008; 8(3):327-32.

11. Oliveira GMF, Ribeiro GA, Oliveira PM, Burgos MEA. Avaliação das atitudes de prevenção de infecção cruzada através de inspeção visual nas clínicas de graduação da Faculdade de Odontologia de Pernambuco - FOP/UPE. Odontol Clín-Cient. 2010; 9(4):349-53.

12. Pimentel MJ, Batista Filho MMV, Santos JP, Rosa MRD. Biossegurança: comportamento dos alunos de Odontologia em relação ao controle de infecção cruzada. Cad Saúde Colet. 2012; 20(4):525-32.

13. Letieri AS, Oshiro NS, Lima LS, Andrade VM, Leão ATT, Torres SR. Avaliação de aderência dos estudantes de Odontologia em relação ao controle de infecções. Rev Bras Odontol. 2011; 68(2):186-90.

\section{CONFLITO DE INTERESSES}

Os autores declaram não haver conflitos de interesse.

\section{AUTOR PARA CORRESPONDÊNCIA}

\section{Najara Barbosa da Rocha}

najararocha@gmail.com

Submetido em 13/09/2017 Aceito em 24/10/2017 